09.1

\title{
Высокоэффективные воспроизводимые зонды для спектроскопии комбинационного рассеяния с усилением на острие (TERS)
}

\author{
() К.Е. Мочалов ${ }^{1}$, Д.О. Соловьева ${ }^{1,2}$, А.Е. Ефримов ${ }^{3,4}$, Д.В. Клинов ${ }^{5}$, В.А. Олейников ${ }^{1,2, q}$ \\ ${ }^{1}$ Институт биоорганической химии им. академиков М.М. Шемякина и Ю.А. Овчинникова РАН, Москва, Россия \\ ${ }^{2}$ Национальный исследовательский ядерный университет „МИФИ“, Москва, Россия \\ ${ }^{3}$ Национальный медицинский исследовательский центр трансплантологии и искусственных органов \\ им. акад. В.И. Шумакова Минздрава России, Москва, Россия \\ ${ }^{4}$ ООО „СНОТРА“, Москва, Россия \\ ${ }_{5}^{5}$ Федеральный научно-клинический центр фризико-химической медицины ФМБА, Москва, Россия \\ 『E-mail: voleinik@mail.ru
}

Поступило в Редакцию 12 мая 2020 г.

В окончательной редакции 28 июля 2020 г.

Принято к публикации 28 июля 2020г.

Основное ограничение применения микроспектроскопии комбинационного рассеяния с усилением на острие (tip-enhanced Raman scattering, TERS) связано с отсутствием надежных сканирующих зондов. Представлена простая методика формирования TERS-зондов с высоковоспроизводимыми характеристиками, надежными и дающими достаточное усиление. Методика основана на модификации стандартных кантилеверов сканирующих зондовых микроскопов плазменным травлением с последующим формированием TERS-усиливающей области на вершине путем осаждения коллоидных наночастиц методом диэлектрофореза.

Ключевые слова: микроспектроскопия комбинационного рассеяния с усилением на острие, TERS, сканирующая зондовая микроскопия, сканирующий зондовый микроскоп $(\mathrm{C} 3 \mathrm{M})$, зонды C3М,

DOI: 10.21883/PJTF.2020.21.50195.18374

Методика микроспектроскопии комбинационного рассеяния с усилением на острие (tip-enhanced Raman scattering, TERS) находит все более широкое применение в различных областях современной науки [1]. Однако широкому внедрению данной методики препятствует ряд нерешенных технических проблем, связанных, в частности, с отсутствием доступной и воспроизводимой методики изготовления TERS-зондов.

Задача остается актуальной, хотя в настоящее время имеются коммерчески доступные TERS-зонды. Однако, несмотря на чрезвычайно высокую цену, нет гарантии не только достаточного усиления, но и их работоспособности. С этим обстоятельством связано большое количество исследований по разработке методик создания TERS-зондов [2-4]. Основная цель настоящей работы состоит в разработке относительно простой, но эффективной методики изготовления TERS-зондов, которая могла бы быть воспроизведена в большинстве заинтересованных в этом лабораторий без существенного их переоборудования.

На данный момент предложен ряд различных методик изготовления TERS-зондов, включающий в себя существенно различающиеся по идеологии подходы [3-5]. Наиболее часто предлагаемыми методами изготовления зондов являются магнетронное и литографическое нанесение усиливающих плазмонных структур, травление металлических (серебро или золото) игл, прикрепление металлических наностержней к стандартным кантилеверам сканирующих зондовых микроскопов (С $3 \mathrm{M})$, создание плазмонных усиливающих структур путем осажде- ния металлических наночастиц в области острия стандартных СЗМ-кантилеверов. Последний из указанных методов видится наиболее перспективным, поскольку технологии изготовления металлических коллоидов в настоящее время хорошо отработаны, а нанесение наночастиц из таких растворов не требует специального и сложного оборудования.

В целом модификация коммерчески доступных СЗМкантилеверов является наиболее перспективной методикой, поскольку они значительно удобнее в обращении, чем иглы, приклеиваемые на кварцевые резонаторы. Известны две основные стратегии нанесения металлических наночастиц из коллоидных растворов: химическое присоединение наночастиц к кремниевой поверхности [6] и осаждение методом диэлектрофореза [7] за счет перемещения электрически нейтральных наночастиц в неоднородном электрическом поле [8]. Однако, как следует из многочисленных экспериментов, этим подходам присущ серьезный недостаток, связанный с малым радиусом кривизны стандартных кантилеверов (около $10 \mathrm{~nm}$ ). Малость радиуса, с одной стороны, обеспечивает получение хороших СЗМ-изображений, но с другой - препятствует уверенному осаждению плазмонных наноструктур. Характерный размер коллоидных наночастиц, например серебра, варьируется в диапазоне 20-70 nm, и такие наночастицы сложно надежно закрепить непосредственно на острие зонда. Это обстоятельство как существенно снижает воспроизводимость методики нанесения (непосредственно кремниевое острие остается непокрытым), так и значительно ухудшает три- 
бологические свойства изготавливаемых TERS-зондов: наночастицы часто отрываются от острия. Отметим, что этот недостаток характерен для обеих методик (как с присоединением коллоидных наночастиц, так и при магнетронном напылении).

Предлагаемый подход основан на предварительном изменении геометрических характеристик острий CЗМ-кантилеверов травлением в Ar-плазме и последующем формировании слоя плазмонных наночастиц на острие зонда, наносимого из коллоидного раствора. Данный подход позволяет существенно увеличить площадь соприкосновения наночастиц в области острия зонда и значительно повысить их адгезию.

Разработанная нами методика изготовления TERSзондов включает два этапа: 1) травление стандартных СЗМ-катилеверов с последующим нанесением серебряного покрытия; 2) осаждение коллоидных наночастиц серебра методом диэлектрофореза.

В качестве исходных были выбраны полуконтактные кремниевые СЗМ-кантилеверы серии VIT_P/IR (http://tipsnano.ru/catalog/afm-special/top-visual/vit-p-ir/) c оптическим доступом сверху. Типичные значения резонансной частоты и силовой константы составляют $300 \mathrm{kHz}$ и $50 \mathrm{~N} / \mathrm{m}$ соответственно. Выбор таких зондов обусловлен тем, что оптический доступ сверху позволяет работать не только в режиме TERS „на просвет“, т. е. с использованием инвертированной схемы, но и в режиме прямого микроскопа с непрозрачными и толстыми образцами. Кроме того, эти зонды имеют золотое отражающее покрытие на внешней стороне балки кантилевера, что дает возможность использования СЗМ-головок с ИК-лазером в системе дефлектометра. Последнее важно для проведения спектральных измерений в видимом диапазоне, поскольку излучение ИК-лазера дефлектометра хорошо отсекается оптическим высокочастотным фильтром.

Плазменная обработка зонда проводилась в атмосфере аргона при давлении около $10^{-2} \mathrm{~Pa}$. Параметры разряда: напряжение $750 \mathrm{~V}$, ток 70-100 $\mathrm{mA}$, расстояние между электродами $200 \mathrm{~mm}$. Время травления $20 \mathrm{~min}$.

Данная процедура позволяет увеличить радиус кривизны исходного зонда до $200 \mathrm{~nm}$. Для лучшей адгезии наночастиц и более эффективного процесса их осаждения на обработанные таким образом зонды наносился слой серебра толщиной около $50 \mathrm{~nm}$.

Коллоидные наночастицы серебра были приготовлены по методике, описанной в [9]. Капля гидрозоля объемом $20 \mu 1$ наносилась на проводящую (золото) подложку, а предварительно обработанный кантилевер закреплялся в СЗМ-головке[7,8]. Обработанный кантилевер подводился к золотой подложке до контакта в режиме обратной связи. Затем отводился на высоту $0.5 \mathrm{~mm}$. Капля гидрозоля наносилась на золотую подложку в непосредственной близости от зонда, и процесс погружения кантилевера контролировался с помощью оптического микроскопа. Процесс нанесения оптимизировался путем варьирования параметров диэлектрофореза: величины приклады-
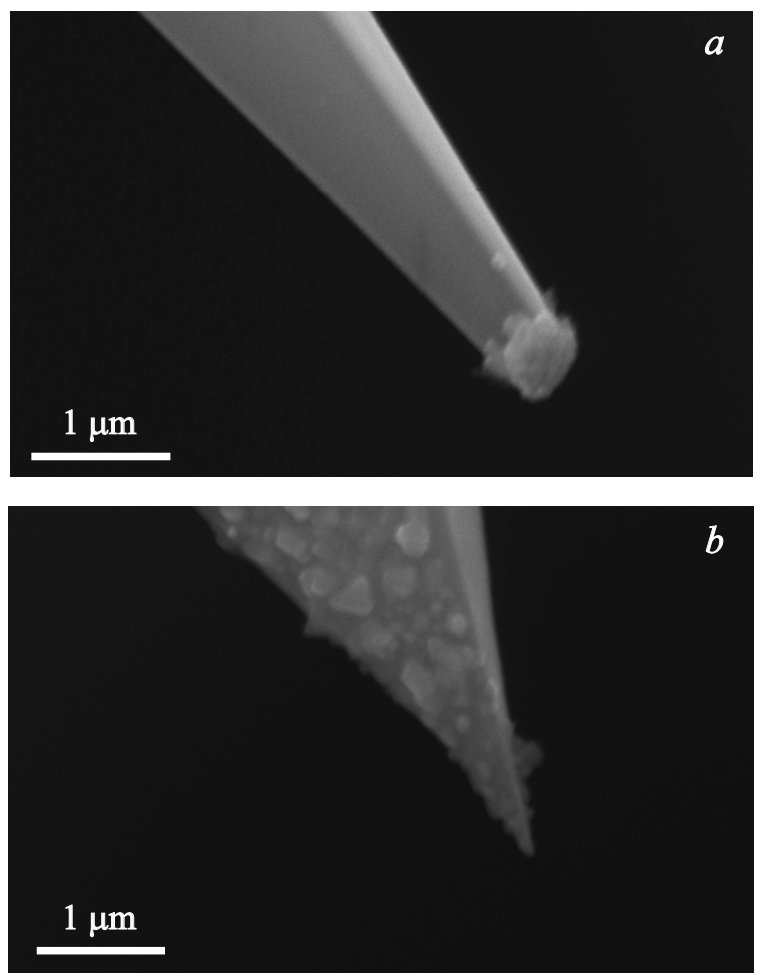

Рис. 1. СЭМ-изображения острий СЗМ-кантилеверов. $a-$ кантилевер c Ag-наночастицами на вершине, сформированный с использованием плазменного травления и оптимальными условиями диэлектрофореза: величина прикладываемого между кантилевером и подложкой переменного напряжения составляет $8.64 \mathrm{~V}$, его частота $150 \mathrm{kHz}$, время выдержки острия зонда в коллоидном растворе $1 \mathrm{~min} . b-$ стандартный СЗМ-кантилевер с осажденными на него Ag-наночастицами.

ваемого между кантилевером и подложкой переменного напряжения (4.4-17.5 V), его частоты $(50-1000 \mathrm{kHz})$ и времени осаждения (0.5-5 min). Контроль полученного результата осуществлялся с помощью метода сканирующей электронной микроскопии (СЭМ) на приборе TESCAN VEGA3. В качестве оптимизируемого параметра осаждения использовалось количество плазмонных наночастиц, локализованных непосредственно на острие зонда.

На рис. 1, $а$ представлено СЭМ-изображение острия СЗМ-кантилевера после его модификации травлением в плазме и осаждения коллоидных наночастиц серебра. Для сравнения на рис. $1, b$ приведено изображение СЗМ-кантилевера с нанесенными наночастицами, но без стадии травления. Видно, что, несмотря на присутствие большого количества наночастиц на боковой поверхности зонда, острие зонда остается непокрытым. Выход высокоэффективных TERS-зондов составляет не менее $90 \%$.

Для оценки аналитических возможностей новых зондов в режиме атомно-силового микроскопа (ACM), а также для получения сигнала TERS в качестве модельных объектов были использованы фрагменты пленок 

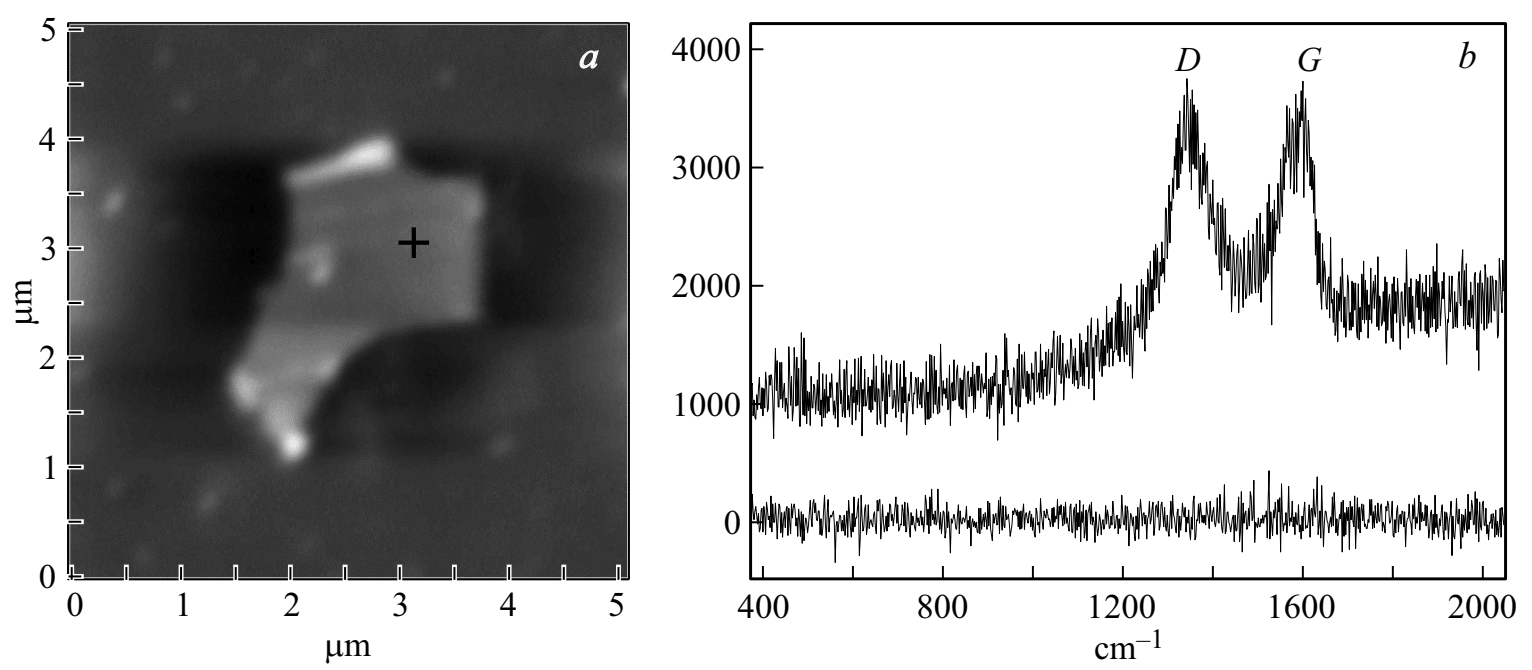

Рис. 2. $a$ - атомно-силовое изображение фрагмента пленки оксида графена, выложенного на покровном стекле, полученное с помощью TERS-кантилевера. Крестиком отмечена область получения TERS-спектра. $b$ - TERS-спектр оксида графена, полученный с использованием TERS-кантилевера (сверху). Линии при 1350 и $1590 \mathrm{~cm}^{-1}$ соответствуют $D$ - и $G$-колебательным модам оксида графена. Нижний спектр - то же, но при удалении TERS-кантилевера от образца.

оксида графена. Фрагменты наносились на поверхность покровных стекол Menzel размером $18 \times 18 \mathrm{~mm}$, тип 1 , из водного раствора, который получался добавлением $1 \mathrm{mg}$ порошка оксида графена (SKU-GO-1G, Graphene Supermarket) к $1 \mathrm{ml}$ бидистиллированной воды с последующим „озвучиванием“ в ультразвуковой ванне в течение часа. После осаждения $20 \mu \mathrm{l}$ раствора оксида графена на поверхность покровного стекла образец высушивался в вакуумном эксикаторе в течение суток.

Критерием оценки качества зондов было сравнение усиления при записи TERS-спектров при использовании разных TERS-катилеверов. Исследования проводились на системе объединенного СЗМ-микроскопа и конфокального микроспектрометра, являющегося частью уникальной научной установки (УНУ, „Система зондово-оптической 3D корреляционной микроскопии“, http://ckp-rf.ru/usu/486825/) [10,11].

Модельный образец помещался на предметный столик конфокального микроспектрометра с установленной на нем СЗМ-головкой (SMENA, NT-MDT). Ввод возбуждающего излучения лазера $\left(\mathrm{Ar}^{+}\right.$, ЛГН-519M, ОАО „Плазма“) и сбор излучения, рассеянного от образца, осуществлялись в инвертированном режиме через объектив 100X/0.80 MPLAPON (Olympus). Подлежащее спектральному анализу излучение с помощью оптической системы, включающей конфокальный модуль, предавалось на монохроматор (Shamrock 750, Andor), оборудованный CCD (DU971P-BV, Andor).

На первом шаге проводилось сканирование модельного образца в режиме АСМ с целью выбора фрагмента пленки оксида графена для дальнейшего получения TERS-спектров (рис. 2,a). Видно, что TERS-зонды позволяют довольно уверенно идентифицировать искомый объект. Процедура совмещения полей зрения
СЗМ-микроскопа и конфокального микроспектрометра, доступная в УНУ „Система зондово-оптической 3D корреляционной микроскопии“ $[10,11]$, позволяет легко сменить TERS-зонд на стандартный CЗМ-кантилевер, сохраняя геометрическое положение исследуемого образца, и, следовательно, вернуться в ту же точку для получения более качественного АСМ-изображения. Пример TERS-спектра приведен на рис. 2, $b$ (верхний спектр). Приведенный спектр хорошо согласуется с ранее опубликованными данными по комбинационному рассеянию и TERS-спектроскопии слоев оксида графена. Хорошо выраженные линии (отношение сигнал/шум не менее 3) при 1350 и $1590 \mathrm{~cm}^{-1}$ соответствуют $D$ - и $G$-колебательным модам оксида графена $[12,13]$.

Оценка воспроизводимости метода выполнялась путем сопоставления результатов ряда TERS-зондов (в данном исследовании мы сравнивали семь зондов) по значению отношения сигнал/шум. При этом для всего ряда были получены АСМ-изображения одного и того же фрагмента пленки оксида графена. TERS-спектры были также записаны от одной и той же области пленки (рис. 2,a). Показано, что разброс значений отношения сигнал/шум для всех TERS-зондов из изготовленной партии не превышал 20\%.

Таким образом, разработанная нами воспроизводимая методика изготовления TERS-зондов позволяет избежать главного недостатка при их производстве - невысокой воспроизводимости начальных характеристик с высокой вероятностью разрушения в процессе сканирования. Использование двухстадийного процесса, включающего этап плазменной обработки, позволяет формировать воспроизводимые зонды с высокой эффективностью получения сигнала TERS. Выбор для модификации стандартных C3M-кантилеверов серии VIT_P/IR с оптиче- 
ским доступом сверху или их аналогов обеспечивает возможность их одинаково эффективного использования во всех возможных режимах TERS-микроспектроскопии: „на просвет“, в режиме прямого микроскопа и при боковой засветке.

\section{Финансирование работы}

Работа выполнена при поддержке Российского научного фонда (проект № 19-14-00171).

\section{Конфликт интересов}

Авторы заявляют, что у них нет конфликта интересов.

\section{Список литературы}

[1] Shao F., Zenobi R. // Anal. Bioanal. Chem. 2019. V. 411. N 1. P. 37-61. DOI: $10.1007 / \mathrm{s} 00216-018-1392-0$

[2] Deckert-Gaudig T., Taguchi A., Kawata S., Deckert V. // Chem. Soc. Rev. 2017. V. 46. N 13. P. 4077-4110. DOI: $10.1039 / \mathrm{c} 7 \mathrm{cs} 00209 \mathrm{~b}$

[3] Yuan C.C., Zhang D., Gan Y. // Rev. Sci. Instrum. 2017. V. 88. N 3. P. 031101 . DOI: $10.1063 / 1.4978929$

[4] Fujita Y., Walke P., De Feyter S., Uji-i H. // Jpn. J. Appl. Phys. 2016. V. 55. N 8S1. P. 08NA02. DOI: $10.7567 /$ jjap.55.08na02

[5] Walke P., Fujita Y., Peeters W., Toyouchi S., Frederickx W., De Feyter S., Uji-i H. // Nanoscale. 2018. V. 10. N 16. P. $7556-$ 7565. DOI: $10.1039 / \mathrm{c} 8 \mathrm{nr} 02225 \mathrm{a}$

[6] Taguchi A., Yu J., Verma P., Kawata S. // Nanoscale. 2015. V. 7. N 41. P. 17424-17433. DOI: $10.1039 / \mathrm{c} 5 \mathrm{nr} 05022 \mathrm{~g}$

[7] Sweetenham C.S., Woolley R.A.J., Notinghe I. // J. Nanophoton. 2016. V. 10. N 3. P. 030502. DOI: 10.1117/1.jnp.10.030502

[8] Leiterer C., Wünsche E., Singh P., Albert J., Köhler J.M., Deckert V., Fritzsche W. // Anal. Bioanal. Chem. 2016. V. 408. N 13. P. 3625-3631. DOI: 10.1007/s00216-016-9447-6

[9] Gakiya-Teruya M., Palomino-Marcelo L., RodriguezReyes J. // J. Meth. Protocols. 2018. V. 2. N 1. P. 3. doi.org/10.3390/mps2010003

[10] Mochalov K.E., Chistyakov A.A., Solovyeva D.O., Mezin A.V., Oleinikov V.A., Vaskan I.S., Molinari M., Agapov I.I., Nabiev I., Efimov F.E. // Ultramicroscopy. 2017. V. 182. P. 118-123. DOI: 10.1016/j.ultramic.2017.06.022

[11] Efimov A.E., Agapov I.I., Agapova O.I., Oleinikov V.A., Mezin A.V., Michael M., Nabiev I., Mochalov K.E. // Rev. Sci. Instrum. 2017. V. 88. N 2. P. 023701. DOI: 10.1063/1.4975202

[12] Kaniyoor A., Ramaprabhu S. // AIP Adv. 2012. V. 2. N 3. P. 032183. DOI: $10.1063 / 1.4756995$

[13] Smolsky J.M., Krasnoslobodtsev A.V. // Nano Res. 2018. V. 11. N 12. P. 6346-6359. DOI: $10.1007 / \mathrm{s} 12274-018-2158-\mathrm{x}$ 